\title{
Alternative Therapeutic Approach in the Treatment of Oral Pyogenic Granuloma
}

\author{
Amr Bugshan Harsh Patel Karen Garber Timothy F. Meiller \\ Department of Oncology and Diagnostic Sciences, Dental School, University of Maryland, \\ Baltimore, Md., USA
}

\section{Key Words}

Gingiva $\cdot$ Pyogenic granuloma $\cdot$ Oral cavity $\cdot$ Steroids $\cdot$ Swelling

\begin{abstract}
Pyogenic granulomas (PGs) in the oral cavity present as an inflammatory hyperplasia usually caused by trauma, hormonal imbalance, chronic irritation, or as the response to a wide variety of drugs. PGs with atypical presentation and behavior may clinically mimic malignant tumors. Thus, histological examination is required to rule out cancer development. Lesions in the oral cavity have been described to be either an isolated entity or present in multiple forms and with multiple recurrences. Conservative surgical excision is the standard choice of treatment in almost every scenario. However, the severity of the lesions and the affected sites often challenge surgical treatment. In this report, we describe the clinical scenario of a recurrent PG, where surgical excision of the lesion was questioned. As an alternative, we describe a noninvasive approach with lesional steroid injections.

(C) 2015 The Author(s)

Published by S. Karger AG, Basel
\end{abstract}

\section{Introduction}

Pyogenic granuloma (PG) was described for the first time in 1879 by Ponect and Dor and was called 'botryomycosis hominis' [1]. Crocker suggested the nomenclature of pyogenic granuloma in 1903 [2]. However, some researchers believe that Hatrzell introduced the term of pyogenic granuloma in 1904 [3]. PG is a common tumor-like growth affecting oral and extraoral sites [4, 5]. Traditionally, these lesions have been considered to be nonneoplastic in nature and thought to represent a tissue growth response to local irritation or trauma $[4,5]$. The name 'pyogenic granuloma' is a misnomer since the condition is not caused by infection, does not associate with 
Bugshan et al:: Alternative Therapeutic Approach in the Treatment of Oral Pyogenic Granuloma

pus clinically and does not histologically represent a granulomatous inflammation $[4,6]$. Clinically, PG is smooth or lobulated, sessile or pedunculated, as well as dull pink to red in color, with occasional surface ulcerations $[4,6]$. Commonly, the lesions are painless but bleed easily due to extreme vascularity [4]. They may develop at any age, but more commonly occur in younger females and children $[4,6]$. Intraorally, the typical site for involvement is the gingiva, with a higher prevalence in the maxilla than in the mandible [4, 6]. Other locations include the lips, buccal mucosa, and tongue [4]. Extraorally, these lesions are more commonly seen on the skin and rarely in the gastrointestinal tract, except the oral cavity [7]. The exact etiopathogenesis remains unexplained, and several factors appear to be related to their formation [8]. Many previous reports have suggested trauma, chronic irritation, hormones, drugs, calculus, foreign material in the gingival crevice, gingival irritation and inflammation caused by poor oral hygiene, and injury to primary teeth to be associated with the initiation of PG $[1,4,9-12]$.

This paper describes our experience in treating a case of recurrent PG with corticosteroids after surgical excision was challenged due to the poor outcome.

\section{Case Report}

A 51-year-old Caucasian female was referred to the Oral Medicine Clinic for the evaluation of recurring PG on the buccal and palatal gingiva between the maxillary right bicuspid teeth. The lesion had been excised 4 times, and the diagnosis was confirmed histologically. The patient was submitted to the Oral Pathology Department at the University of Maryland Baltimore. Microscopic examination of different recurrent tissue specimens of the same lesion, using hematoxylin and eosin stain (H\&E), revealed hyperplastic surface epithelium with highly vascular proliferation that resembles granulation tissue with numerous small and large endothelium-lined channels (fig. 1a). Mixed inflammatory cell infiltrates containing neutrophils, lymphocytes, and macrophages were observed (fig. 1b). All previous biopsy specimens were defined as PG. After 4 recurrences, the patient was referred to the Oral Medicine Clinic for further follow-up (the patient's past medical history was unremarkable and noncontributory). On the initial visit, she presented with a recurrent reddish, asymptomatic gingival growth measuring $0.9 \times 0.6 \mathrm{~cm}$ on the buccal and $0.8 \times 0.7 \mathrm{~cm}$ on the palatal aspect between the maxillary bicuspids (fig. 2a). Intralesional injections of $0.1 \mathrm{ml} \mathrm{of} 10 \mathrm{mg} / \mathrm{ml}$ triamcinolone acetonide injectable suspension (Kenalog-10) were performed at each of 5 different sites, with the total volume not exceeding $0.5 \mathrm{ml}$, and the patient was advised to use $0.05 \%$ clobetasol propionate ointment to be applied locally for 2 weeks. On the subsequent visit, after 3 weeks, the lesion had disappeared completely, and there was no recurrence. At the follow-up visit, the lesion had not recurred for a total of 6 weeks. Kenalog injections were no longer necessary at this time (fig. $2 \mathrm{~b}$ ). Also, the patient was instructed to discontinue the use of clobetasol ointment.

\section{Discussion}

The study by Bhaskar et al. [2] of 242 patients with different oral lesions showed that PG was reported in $1.85 \%$ of all oral pathoses. Gingival lesions of 153 cases in the Southern Indian population were retrospectively analyzed. The authors found that $51 \%$ of gingival lesions were nonneoplastic, and PG was the most common diagnosis, accounting for $42.3 \%$ [13]. PGs can be treated in different ways, but conservative surgical excision and the removal of irritation factors are the usual treatment $[4,6]$. For gingival lesions, excision should be 
Bugshan et al.: Alternative Therapeutic Approach in the Treatment of Oral Pyogenic Granuloma

extended deeply to the periosteum and adjacent teeth to remove the irritation source and prevent lesion recurrence [4]. Occasionally, PG recurs after surgical excision, and reexcision should be done. The recurrence rate after surgical treatment was noted to be $15.8 \%$ in a retrospective study of 242 cases, and it is more common after the excision of gingival lesions compared to the extragingival sites [2]. This unusual phenomenon of multiple PGs is known as satellitosis and usually develops as a complication of tumor removal or trauma $[14,15]$.

Other treatment options for PG have been introduced to replace surgical excision. In 1998, White et al. [16] showed that laser excision of PG is well tolerated by patients, with minimal side effects. Cryosurgery or the use of an electric scalpel has been reported to help in the complete resolution of PG [17]. Further, local injections of a sclerosing agent (monoethanolamine oleate) aided in the complete disappearance, with no recurrence in 9 patients [18]. Local injection of ethanol also appears to be an alternative therapy for PG [19]. Two extraoral PGs were reported to be reduced in size after multiple local intralesional steroid injections [20]. In 2004, Tursen et al. [21] reported a case with recurrent giant PG on the face, which had regressed in response to oral administration of systemic steroid treatment (prednisolone). In 2006, Parisi et al. [22] first described the use of a series of intralesional corticosteroid injections to treat multiple nodules of intraoral PGs, elucidating the new conservative treatment option. The exact mechanism of action of corticosteroid therapy is unknown. Corticosteroids might enhance the response of the lesion in the vascular bed to vasoconstricting agents [23]. In vitro and in vivo studies of hemangioma-derived stem cells showed that dexamethasone treatment inhibits the vasculogenic potential of hemangiomaderived stem cells. Also, dexamethasone arrests the vascular proliferation by downregulation of proangiogenic factors such as VEGF-A, MMP1, and IL-6 [24].

Based on this report, it can be inferred that multiple etiological factors might have played a role in the development of these large or recurrent lesions. However, treatment choice should consider the esthetic and functional improvement of the soft tissues with minimum invasion. Thus, we treated our case with a combination of antibiotics and steroids in order to relieve the microbial load of the lesions and gain maximum anti-inflammatory effects of the steroids to regress the lesion. Three weeks after the first visit, the lesion was completely healed. At the follow-up appointment, there was no recurrence, the patient was advised to discontinue both topical and local injections of steroids, and was placed on recall.

The drawbacks of our approach include the increased duration of disease management and, if this approach is used at the first clinical presentation, eliminate a histologically confirmed diagnosis prior to treatment. We recommend that in the treatment of PGs, the initial diagnosis should be confirmed histologically as they can be underdiagnosed for other more aggressive and even malignant lesions. However, when such lesions recur, a steroid management approach may be appropriate and safe. We conclude that steroid management may be considered as an alternative treatment approach for highly recurrent PGs in patients with proper medical and clinical evaluation.

\section{Statement of Ethics}

The patient described in this case report was a registered patient of the University of Maryland Oral Medicine Program. As such, she completed the general informed consent process for diagnosis and treatment. Further, she also provided informed consent for the experimental treatment evaluated in this report as an alternative to additional surgical interventions. All activities of this nature are fully reviewed and approved by the University Institutional Review Board. 
Bugshan et al.: Alternative Therapeutic Approach in the Treatment of Oral Pyogenic Granuloma

\section{Disclosure Statement}

The submitted documents represent original research that has not been published previously in any form, and it is not currently submitted for publication elsewhere. All authors have read and approved the manuscript. We also report no conflicts of interest.

\section{References}

1 Jafarzadeh H, Sanatkhani M, Mohtasham N: Oral pyogenic granuloma: a review. J Oral Sci 2006;48:167-175.

2 Bhaskar SN, Jacoway JR: Pyogenic granuloma - clinical features, incidence, histology, and result of treatment: report of 242 cases. J Oral Surg 1966;24:391-398.

-3 Angelopoulos AP: Pyogenic granuloma of the oral cavity: statistical analysis of its clinical features. J Oral Surg 1971;29:840-847.

4 Nevile BW, Damm DD, Allen CM, Bouquot JE: Oral and Maxillofacial Pathology, ed 3. St. Louis, Saunders, 2009.

-5 Vilmann A, Vilmann P, Vilmann H: Pyogenic granuloma: evaluation of oral conditions. Br J Oral Maxillofac Surg 1986;24:376-382.

6 Regezi JA, Sciubba J, Jordan RCK: Oral Pathology: Clinical Pathologic Considerations, ed 4. Philadelphia, Saunders, 2003.

-7 Yao T, Nagai E, Utsunomiya T, Tsuneyoshi M: An intestinal counterpart of pyogenic granuloma of the skin. A newly proposed entity. Am J Surg Pathol 1995;19:1054-1060.

8 Mooney MA, Janniger CK: Pyogenic granuloma. Cutis 1995;55:133-136.

$\checkmark 9$ Chandrashekar B: Minimally invasive approach to eliminate pyogenic granuloma: a case report. Case Rep Dent 2012;2012:909780.

10 Kamal R, Dahiya P, Puri A: Oral pyogenic granuloma: various concepts of etiopathogenesis. J Oral Maxillofac Pathol 2012;16:79-82.

11 Greenberg MS, Ship JA, Glick M: Burket's Oral Medicine: Diagnosis and Treatment, ed 10. Hamilton, BC Decker, 2003.

12 Milano M, Flaitz CM, Bennett J: Pyogenic granuloma associated with aberrant tooth development. Texas Dent J 2001;118:166-172.

13 Kamath KP, Vidya M, Anand PS: Biopsied lesions of the gingiva in a southern Indian population - a retrospective study. Oral Health Prev Dent 2013;11:71-79.

-14 Zaynoun ST, Juljulian HH, Kurban AK: Pyogenic granuloma with multiple satellites. Arch Dermatol 1974;109:689-691.

15 Taira JW, Hill TL, Everett MA: Lobular capillary hemangioma (pyogenic granuloma) with satellitosis. J Am Acad Dermatol 1992;27:297-300.

16 White JM, Chaudhry SI, Kudler JJ, Sekandari N, Schoelch ML, Silverman S Jr: Nd:YAG and $\mathrm{CO}_{2}$ laser therapy of oral mucosal lesions. J Clin Laser Med Surg 1998;16:299-304.

17 Mirshams M, Daneshpazhooh M, Mirshekari A, Taheri A, Mansoori P, Hekmat S: Cryotherapy in the treatment of pyogenic granuloma. J Eur Acad Dermatol Venereol 2006;20:788-790.

18 Matsumoto K, Nakanishi H, Seike T, Koizumi Y, Mihara K, Kubo Y: Treatment of pyogenic granuloma with a sclerosing agent. Dermatol Surg 2001;27:521-523.

19 Ichimiya M, Yoshikawa Y, Hamamoto Y, Muto M: Successful treatment of pyogenic granuloma with injection of absolute ethanol. J Dermatol 2004;31:342-344.

20 Niiyama S, Amoh Y, Katsuoka K: Pyogenic granuloma that responded to local injection of steroid. J Plast Reconstr Aesthet Surg 2009;62:e153-e154.

-21 Tursen U, Demirkan F, Ikizoglu G: Giant recurrent pyogenic granuloma on the face with satellitosis responsive to systemic steroids. Clin Exp Dermatol 2004;29:40-41.

-22 Parisi E, Glick PH, Glick M: Recurrent intraoral pyogenic granuloma with satellitosis treated with corticosteroids. Oral Dis 2006;12:70-72.

23 Edgerton MT: The treatment of hemangiomas: with special reference to the role of steroid therapy. Ann Surg 1976;183:517-532.

24 Greenberger S, Boscolo E, Adini I, Mulliken JB, Bischoff J: Corticosteroid suppression of VEGF-A in infantile hemangioma-derived stem cells. N Engl J Med 2010;362:1005-1013. 


\section{Case Reports in Oncology}

\begin{tabular}{l|l}
\hline Case Rep Oncol 2015;8:493-497 \\
\hline DOI: 10.1159/000441839 & $\begin{array}{l}\text { (c) 2015 The Author(s). Published by S. Karger AG, Basel } \\
\text { www.karger.com/cro }\end{array}$ \\
\hline
\end{tabular}

Bugshan et al.: Alternative Therapeutic Approach in the Treatment of Oral Pyogenic Granuloma
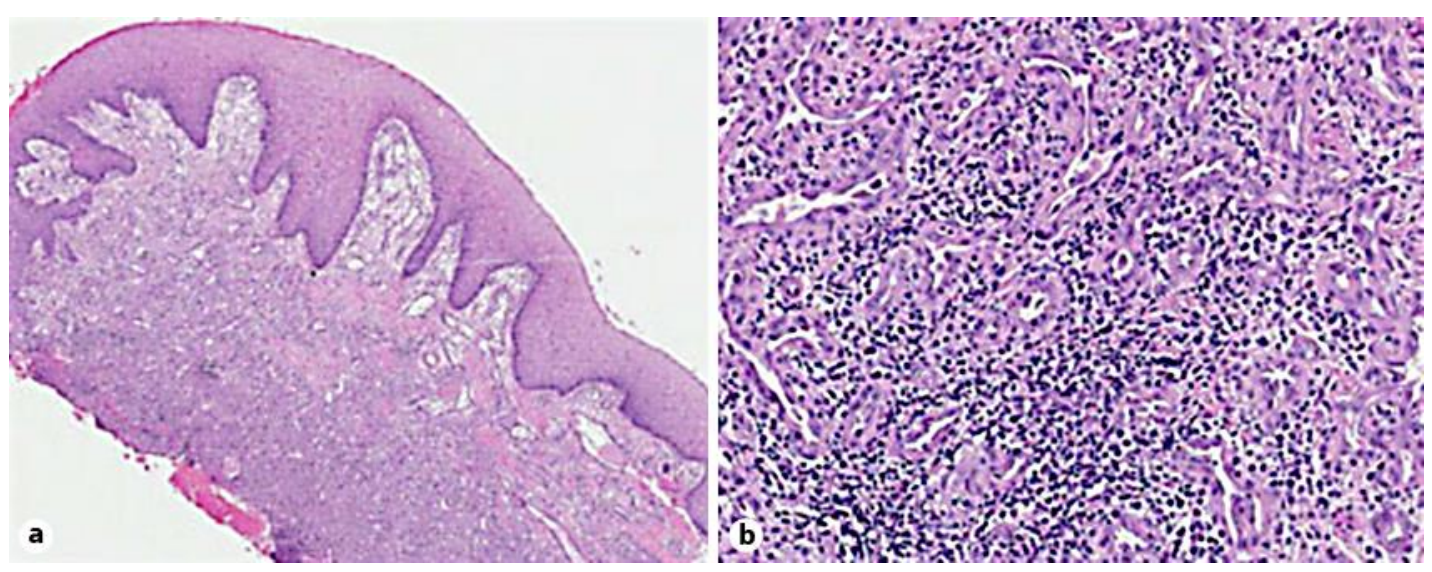

Fig. 1. Biopsy of the palatal gingiva between the maxillary right bicuspid teeth. a Photomicrograph showing hyperplastic surface epithelium with vascular proliferation and mixed inflammatory cells. H\&E. $\times 10$. b Photomicrograph showing small and large endothelium-lined channels and mixed inflammatory cell infiltrate. H\&E. $\times 40$.
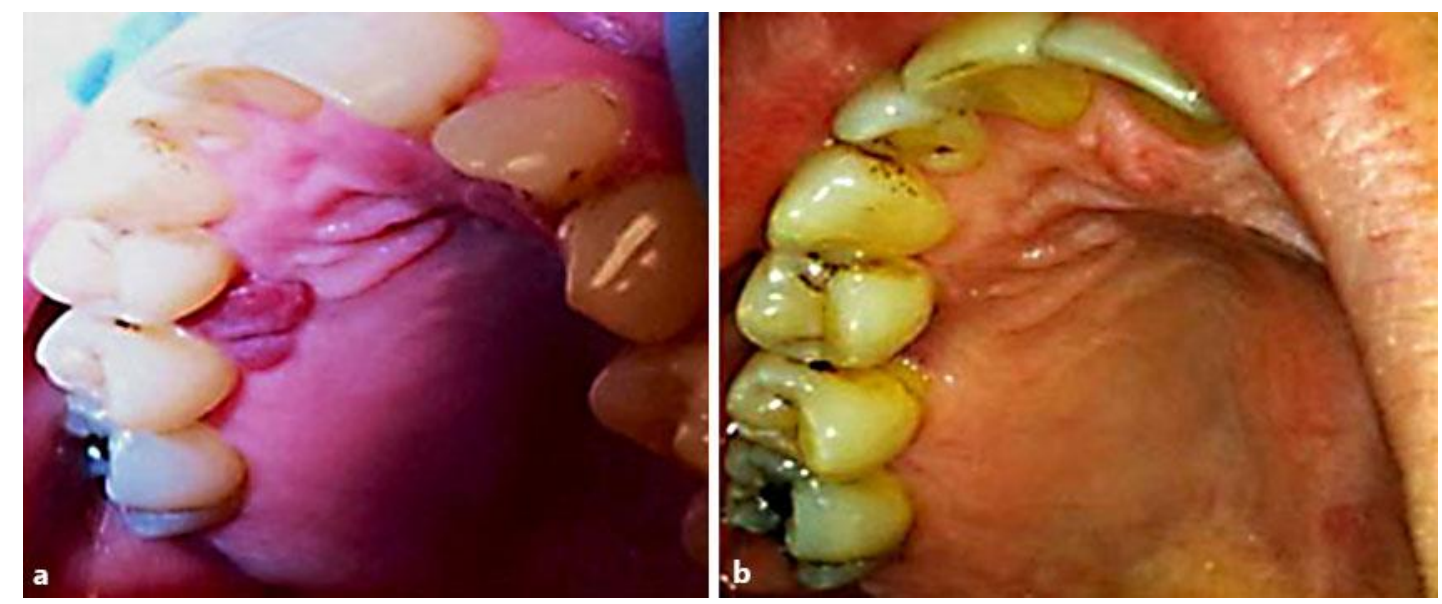

Fig. 2. Palatal gingiva. a Photograph showing $0.8 \times 0.7 \mathrm{~cm}$ gingival growth on the palatal aspects between the maxillary bicuspids (before intralesional steroid injection). b Photograph showing disappearance of the lesions 3 weeks after steroid intralesional injection. 